(2) Open Access Full Text Article

\title{
Preparation and in vivo absorption evaluation of spray dried powders containing salmon calcitonin loaded chitosan nanoparticles for pulmonary delivery
}

\author{
This article was published in the following Dove Press journal: \\ Drug Design, Development and Therapy \\ 27 August 2013 \\ Number of times this article has been viewed
}

\section{Chutima Sinsuebpol \\ Jittima Chatchawalsaisin \\ Poj Kulvanich}

Department of Pharmaceutics and Industrial Pharmacy, Faculty of Pharmaceutical Sciences,

Chulalongkorn University, Bangkok, Thailand
Correspondence: Poj Kulvanich

Department of Pharmaceutics and Industrial Pharmacy, Faculty of

Pharmaceutical Sciences, Chulalongkorn University, 254 Phayathai Road,

Pathumwan, Bangkok 10330, Thailand

Tel +66 89 921 2096

Fax +6622188279

Email kpoj@chula.ac.th
Purpose: The aim of the present study was to prepare inhalable co-spray dried powders of salmon calcitonin loaded chitosan nanoparticles (sCT-CS-NPs) with mannitol and investigate pulmonary absorption in rats.

Methods: The sCT-CS-NPs were prepared by the ionic gelation method using sodium tripolyphosphate (TPP) as a cross-linking polyion. Inhalable dry powders were obtained by co-spray drying aqueous dispersion of sCT-CS-NPs and mannitol. sCT-CS-NPs co-spray dried powders were characterized with respect to morphology, particle size, powder density, aerodynamic diameter, protein integrity, in vitro release of $\mathrm{sCT}$, and aerosolization. The plasmatic $\mathrm{sCT}$ levels following intratracheal administration of sCT-CS-NPs spray dried powders to the rats was also determined.

Results: sCT-CS-NPs were able to be incorporated into mannitol forming inhalable microparticles by the spray drying process. The sCT-CS-NPs/mannitol ratios and spray drying process affected the properties of the microparticles obtained. The conformation of the secondary structures of sCTs was affected by both mannitol content and spray dry inlet temperature. The SCT-CS-NPs were recovered after reconstitution of spray dried powders in an aqueous medium. The sCT release profile from spray dried powders was similar to that from sCT-CS-NPs. In vitro inhalation parameters measured by the Andersen cascade impactor indicated sCT-CSNPs spray dried powders having promising aerodynamic properties for deposition in the deep lung. Determination of the plasmatic sCT levels following intratracheal administration to rats revealed that the inhalable sCT-CS NPs spray dried powders provided higher protein absorption compared to native SCT powders.

Conclusion: The sCT-CS-NPs with mannitol based spray dried powders were prepared to have appropriate aerodynamic properties for pulmonary delivery. The developed system was able to deliver SCT via a pulmonary route into the systemic circulation.

Keywords: Salmon calcitonin, chitosan, nanoparticles, mannitol, spray dried powders, pulmonary delivery

\section{Introduction}

Pulmonary delivery is a potentially non-invasive administration route for peptide and protein drugs for systemic treatments. ${ }^{1}$ Proteins and macromolecules are absorbed more through this route because the lung possesses a large and highly absorptive surface area, extensive vascularization, and low thickness of the alveolar epithelium. Lung alveolar surface varies between $80-140 \mathrm{~m}^{2}$, larger than that of the nose which is estimated to be about $180 \mathrm{~cm}^{2}$. The distance between epithelial surface and blood 
circulation is between 0.5 and $1.0 \mu \mathrm{m}$, which is much less than the other regions of respiratory tract. In addition, it has low enzymatic action and also avoids hepatic first pass metabolism. ${ }^{1,2}$

Salmon calcitonin (sCT) is a 32 amino acid cyclic polypeptide with a molecular weight of approximately 3,450 Da, available as a high potency therapeutic agent to treat osteoporosis, hypercalcemia, symptomatic Paget's disease of bone, and osteoarthritis. ${ }^{3}$ It has been commercialized in the form of subcutaneous or intramuscular injections and nasal sprays. Injectable dosage form often discourages patients' usage due to pain experienced during injection and resulting facial flushes and nausea. ${ }^{4}$ Nasal delivery was established for simple administration. However, some drawbacks of nasal formulations including irritation to nasal mucosa, rhinitis, rhinorrhea, and allergic rhinitis have been reported. ${ }^{5}$ These drawbacks are unavoidable since the nasal spray formulations inevitably contain absorption enhancers to increase trans-mucosal calcitonin delivery. Many studies also reported a low systemic bioavailability of therapeutic protein administered nasally, requiring a high dose to be taken. ${ }^{6}$ Nasal bioavailability was particularly restricted by characteristics of the drug molecule, rapid enzyme degradation in nasal cavity, poor membrane penetration, and rapid mucociliar clearance. ${ }^{7}$ The intranasal sCT bioavailability was very low, approximately $3 \%$, although an absorption enhancer was used in the formulation. ${ }^{8}$ In addition, the disadvantage is that most commercial $\mathrm{sCT}$ products formulated in aqueous solution dosage form are prone to instability, and hence required to be kept under refrigerated conditions. As protein or peptide drugs are more stable in the solid state, dry powders for inhalation have been explored as an alternative delivery system for $\mathrm{sCT} .{ }^{9,10}$ Limitations of nasal delivery regarding low drug bioavailability may be improved by administration through the pulmonary route.

Nanoparticles are of interest as a carrier of proteins and macromolecules for pulmonary delivery due to their capacity to penetrate into intracellular compartments and the possibility of avoiding phagocytosis of macrophages. They can also have high drug loading capacity, improved drug absorption, differently targeted deposition, and sustained release property. ${ }^{11}$ However, the use of nanoparticles itself for delivery to the lung is limited by the low inertia causing them to be exhaled after inhalation, and its high free surface energy, promoting the particles to form aggregation making nanoparticulates difficult to handle. ${ }^{12}$ Therefore, to make the nanoparticles applicable in the pulmonary delivery system, they require a carrier to achieve effective aerosolization properties.
Spray drying is a useful technique to prepare microparticles for inhalation. It is a rapid, single step process that converts liquid droplets to powders suitable for pulmonary delivery. Sham et al employed the spray drying method to incorporate polymeric nanoparticles into the matrix carrier, forming microparticles for delivery to the lung. ${ }^{13}$ The excipients, such as lactose or mannitol, have been employed as carriers for inhalable dry powder formulations. ${ }^{14,15}$ However, mannitol was found to be more attractive than lactose because of less hygroscopicity and no reducing effect. Mannitol also has the capacity to provide a high fine particle dose of incorporated drug upon powder aerosolization. ${ }^{16}$ Spray drying was found to be a method of choice for particle engineering of powder to have optimum particle characteristics, including size and density for effective deposition mechanism. ${ }^{17}$ For deep lung deposition, spray dried powders demonstrate adequate aerodynamic properties, ie, aerodynamic diameter of less than $5 \mu \mathrm{m}$.

Chitosan (CS) is a polysaccharide biopolymer, similar in structure to cellulose. It is obtained from deacetylation of chitin, abundantly found in the crustaceans' shells. The cationic nature of this polymer is an interesting property because of its ability to form gel through ionic gelation when contacted with polyanions. Several studies applied this gelation process in preparing chitosan nanoparticles for drug encapsulation. A simple and straightforward procedure is based on the gelation of chitosan with the counter-ion tripolyphosphate (TPP), in which the positively charged amino groups of CS interact with negatively charged TPP to form an ionic complex. ${ }^{18-21}$ It is a mild process avoiding use of harmful solvents for encapsulation of proteins. CS was proved to be useful for nanoparticulate drug delivery via transmucosal route due to its low toxicity, biocompatibility, biodegradability, and mucoadhesive properties ${ }^{18,22}$ as well as enhancement of macromolecule permeation. ${ }^{23} \mathrm{CS}$ has been reported to increase the uptake of macromolecules through the opening of tight junctions of epithelial cells and has been formulated as nanoparticles to improve the delivery of active molecules across mucosal surfaces. ${ }^{18,19}$ Spray dried CS nanoparticles have been shown to exhibit a low toxicity in cell lines of human origin from airway and alveolar regions of the pulmonary tract, which is an encouraging indicator for safe use of this dry powder for inhalation. ${ }^{24}$

In this study, the spray dried powders of $\mathrm{sCT}$ loaded chitosan nanoparticles (sCT-CS-NPs) were prepared using mannitol as an aerosol carrier. sCT was loaded into $\mathrm{CS} / \mathrm{TPP}$ nanoparticles that were fabricated by ionic gelation. sCT-CS-NPs and mannitol aqueous suspensions were 
co-spray dried to achieve micro-sized powders suitable for inhalation. Finally, an in vivo animal study in rats was carried out to demonstrate that the developed system was able to deliver $\mathrm{SCT}$ via the pulmonary route.

\section{Materials and methods Materials}

sCT (molecular weight of 3,431.90 Da) was purchased from Bachem AG (Buendrof, Switzerland). Low molecular weight CS of $75 \%-85 \%$ deacetylation, TPP, D-mannitol, 2-mercaptoethanol, Tris base $\left(\right.$ Trizma $\left.^{\circledR}\right)$, acrylamide/bisacrylamide, Tris-Tricine-SDS running buffer, EZBlue ${ }^{\mathrm{TM}}$ gel staining reagent, ammonium persulfate, glycine, trifluoroacetic acid and urethane were purchased from Sigma Aldrich (St Louis, MO, USA). Acetonitrile and methanol of high-performance liquid chromatography (HPLC) grade were purchased from Honeywell Berdick and Jackson (Ulsan, Korea). An enzyme-linked immunosorbent assay (ELISA) kit for sCT was purchased from Uscn Life Science Inc (Wuhan, People's Republic of China).

\section{Preparation of sCT-CS-NPs}

sCT-CS-NPs were prepared based on the ionic gelation of CS with TPP. ${ }^{18,19}$ Briefly, CS was dissolved in $1 \%$ (weight/volume) acetic solution to obtain the solution of $2.07 \mathrm{mg} / \mathrm{mL}$. TPP was dissolved in water to obtain the solution of $0.69 \mathrm{mg} / \mathrm{mL}$. sCT was premixed with TPP solution to generate a nanoparticle dispersion of $1 \mathrm{mg} / \mathrm{mL}$ concentration. The solution of sCT-TPP was added to CS solution to obtain theoretical CS to TPP weight ratios of $3: 1$. The solution $\mathrm{pH}$ was adjusted to 4.5 using $0.1 \mathrm{~N}$ sodium hydroxide. The nanoparticles were spontaneously formed upon adding the TPP solution into the CS solution under mild stirring. The nanoparticle dispersions were gently stirred for 60 minutes at ambient temperature.

\section{Preparation of sCT-CS-NPs spray dried powders}

Aqueous solutions of mannitol in a concentration of 7\%-9\% (weight/volume) were prepared. Nanoparticle dispersion was added to the mannitol solution. Concentrations of the mannitol solution were varied in order to obtain final weight ratios of sCT-CS-NPs to mannitol at 10:90, 20:80, 30:70 and a final total solid content of dispersion at $1 \%$ (weight/volume). The dispersion was spray dried using a laboratory scale spray dryer (Mini Spray Dryer, B-290, BÜCHI Labortechnik AG, Flawil, Switzerland). The liquid was peristaltically pumped and fed through a two-fluid nozzle ( $0.5 \mathrm{~mm}$ internal diameter) where it was atomized into fine droplets. Cooling water was circulated through the jacket around the nozzle throughout the process. The processing parameters comprising atomizing air volumetric flow rate of $600 \mathrm{~nL} /$ hour, aspirator vacuum of $80 \mathrm{mbar}$, liquid feed rate of $5 \mathrm{~mL} /$ minutes was kept constant, while inlet air temperatures were varied at $110^{\circ} \mathrm{C}, 130^{\circ} \mathrm{C}$ and $150^{\circ} \mathrm{C}$ in order to investigate the effect of drying temperature. The spray dried powders were collected and stored in a dessicator until use.

\section{Characterization of spray dried powders Yield}

The spray drying production yield (PY) was calculated by comparing the amount of sCT-CS-NPs spray dried powders with the total amount of initial solid contents in the dispersion as follows:

PY $(\%)=\frac{\text { Weight of spray dried powders }}{\text { Total solid weight of sCT - CS - NPsand mannitol }} \times 100$

\section{Morphology}

The morphology of sCT-CS-NPs spray dried powders was viewed using a scanning electron microscope (SEM; JSM6610 LV, Jeol Ltd, Tokyo, Japan).

\section{Particle size determination}

Particle size analysis was conducted using a laser diffraction particle size analyzer (Malvern Mastersizer ${ }^{\circledR} \mathrm{S}$, Malvern Instruments Ltd, Malvern, UK). The volume mean diameter (VMD), and other particle size parameters corresponding to the size of the 10th, 50th and 90th percentile of particles cumulative volume $\left(\mathrm{D}_{0.1}, \mathrm{D}_{0.5}\right.$, and $\mathrm{D}_{0.9}$, respectively) and span $\left[\left(\mathrm{D}_{0.9}-\mathrm{D}_{0.1}\right) / \mathrm{D}_{0.5}\right]$ were determined. Samples were prepared by suspending the sCT-CS-NPs spray dried powders in ethanol with aid of sonication for 2 minutes. Measurements were repeated to ensure that no dissolution or agglomeration of the powders obtained. Each sample was determined in triplicate.

\section{Powder density and calculated aerodynamic properties}

True density of powders was determined using a helium pycnometer (Ultrapycnometer 1000, Quantachrome Instruments, Dayton Beach, FL, USA). Approximately, $1 \mathrm{~g}$ of each powder sample was used. The mean value of three determinations is reported. 
The bulk and tapped densities were measured. Carr's index percentage (CI) was calculated and employed as an indication of flowability of the samples. The powders were filled into a $10 \mathrm{~mL}$ measuring cylinder. After recording the bulk volume, the cylinder was tapped 100 times and the tapped volume was recorded. The preliminary results showed that the use of 100 taps was sufficient to attain the minimum volume of the powders under study. CI and the aerodynamic diameter $\left(\mathrm{d}_{\text {aer }}\right)$ of dry powder were calculated using the following equations:

$$
\text { Carr'sindex }(\%)=\frac{\rho_{t}-\rho_{b}}{\rho_{t}} \times 100
$$

where $\rho_{t}$ is the tapped density and $\rho_{b}$ is the bulk density $\left(\mathrm{g} / \mathrm{cm}^{3}\right)$

$$
d_{\text {aer }}=\mathrm{D}_{(0.5)} \times \sqrt{\frac{\rho_{t}}{\rho_{0}}}
$$

where $\mathrm{D}_{(0.5)}$ is the equivalent volume diameter at $50 \%$ cumulative volume, $\rho_{t}$ is the tapped density, and $\rho_{0}$ is true density $\left(\mathrm{g} / \mathrm{cm}^{3}\right)$.

\section{Sodium dodecyl sulfate-polyacrylamide gel electrophoresis (SDS-PAGE) analysis}

$\mathrm{SCT}$ in spray dried powders was recovered by dispersing the powders in $\mathrm{pH} 4.4$ acetate buffer. One part of the dispersed sample was mixed with one part of reducing sample buffer, ie, $5 \% \beta$-mercaptoethanol in Tris-HCl-SDS sample buffer, and heated at $100^{\circ} \mathrm{C}$ for 1 minute. The mixture equivalent to $0.5 \mu \mathrm{g}$ of sCT was then loaded into $20 \%$ (weight/volume) Bis-Tris polyacrylamide gel of $\mathrm{pH} 8.8$ and subjected to electrophoresis (Bio-Rad model Mini-Protean III, Bio-Rad Laboratories, Hercules, CA, USA) in Tris-Tricine-SDS running buffer, at $200 \mathrm{~V}$ for about 45 minutes. The gel was stained with EZBlueTM gel staining reagent for 1 hour and destained several times with distilled water until the protein bands were visualized.

\section{Circular dichroism (CD) spectroscopy}

Conformational structure of sCT was investigated by spectropolarimeter (JASCO model J-715, Jasco, Tokyo, Japan) using a quartz cell with $0.1 \mathrm{~cm}$ of path length. The study was performed for sCT, sCT-CS-NPs, and sCT-CS-NPs spray dried powders. Before analysis, the spray dried powders were diluted with ultrapure water to obtain about $50 \mu \mathrm{g} / \mathrm{mL}$ of sCT in solution. Data were collected at bandwidth of $1.0 \mathrm{~nm}$, response of 4 seconds, and a scanning speed of $100 \mathrm{~nm} /$ minute. Each measurement was repeated at least three times and the average value was determined. Spectra were displayed as the plot of molar ellipticity against wavelength.

\section{Fourier transform infrared (FTIR) spectroscopy}

Structural change of the $\mathrm{SCT}$ in sCT-CS-NPs and SCTCS-NPs spray dried powders were monitored by FTIR spectroscopy (Perkin-Elmer FTIR spectrometer, model Spectrum One, Waltham, MA, USA). A small amount of sample was mixed with $\mathrm{KBr}$ and compressed to form tablets. The IR spectra were obtained in the spectral region of $400-4,000 \mathrm{~cm}^{-1}$.

\section{Nanoparticles recovery from spray dried powders in aqueous medium}

Approximately $50 \mathrm{mg}$ of the spray dried powders were incubated in $3 \mathrm{~mL}$ of PBS pH 7.4 for 90 minutes, under mild magnetic stirring at room temperature. The morphology, size, and zeta potential of nanoparticles were analyzed using a transmission electron microscope (TEM, JEM-2100, JEOL Ltd), photon correlation spectroscopy and laser doppler anemometry (Zetasizer ${ }^{\circledR}$ Nano-ZS, Malvern Instruments Ltd, Malvern, UK), respectively $(\mathrm{n}=3)$.

\section{In vitro release of $\mathrm{sCT}$ from nanoparticles}

The release of sCT was evaluated by incubating the sCTCS-NPs or sCT-CS-NPs spray dried powders in $5 \mathrm{~mL}$ of phosphate buffer $\mathrm{pH} 7.4$ at $37^{\circ} \mathrm{C} \pm 1^{\circ} \mathrm{C}$. At time intervals of $5,10,15,30,45,60$, and 90 minutes, $100 \mu \mathrm{L}$ of withdrawn supernatant was passed through a low protein binding filter with pore size $0.22 \mu \mathrm{m}$ (Millipore, Billerica, MA, USA) and the amount of protein released was analyzed by validated HPLC method with an ultraviolet (UV) detector (LC-20A, Shimadzu, Kyoto, Japan). The chromatographic conditions were modified from the method described by Yang et al. ${ }^{10}$ The elution was achieved with gradient of $0.1 \%$ trifluoroacetic acid in water (A) and $0.1 \%$ trifluoroacetic acid (TFA) in acetonitrile (B). The amount of phase B was increased from $25 \%$ to $75 \%$ over 45 minutes with a flow rate of $1.0 \mathrm{~mL} /$ minute. The sample injection volume was $50 \mu \mathrm{L}$ and the eluent was monitored at $220 \mathrm{~nm}$. Each sample was determined in triplicate.

\section{In vitro dry powders aerosolization and deposition}

Aerosolization and deposition properties of the spray dried powders were investigated using an Andersen Cascade Impactor (ACI; Copley Scientific Ltd, Nottingham, UK). 
Before measurement, all parts of the ACI were washed and dried. The collection plates were subsequently immersed in $1 \%$ glycerol in acetone solution and the solvent was allowed to evaporate to leave a thin film of glycerol on the surface of the plates to avoid particle bounce. The ACI was then assembled and the air flow rate through the impactor was adjusted to $60 \mathrm{~L} / \mathrm{minute}$. At this flow rate, the effective cutoff diameters of the modified ACI are: stage $(-1), 8.6 \mu \mathrm{m}$; stage (0), $6.5 \mu \mathrm{m}$; stage (1), $4.4 \mu \mathrm{m}$; stage (2), $3.2 \mu \mathrm{m}$; stage (3), $1.9 \mu \mathrm{m}$; stage (4), $1.2 \mu \mathrm{m}$; stage (5), $0.55 \mu \mathrm{m}$ and stage (6), $0.26 \mu \mathrm{m}$, respectively.

Powder sample was aerosolized from a glass inhaler device connected to the ACI apparatus. The glass inhaler device was loaded with $20 \mathrm{mg}$ of sample. In each deposition experiment, five aerosolizations were carried out. The deposition experiment was performed in triplicate. After that, each stage of the ACI was rinsed with HPLC mobile phase, and made up to a $10 \mathrm{~mL}$ final volume. The mass of sCT deposited on each stage of the ACI was assayed using HPLC as previously described. The fine particle dose (FPD), defined as the mass of drug less than $5 \mu \mathrm{m}$, was calculated by interpolation from a plot of cumulative mass versus effective cut-off diameter of the respective stages. The fine particle fraction (FPF) was calculated as the ratio of FPD to total loaded dose, expressed as a percentage and corrected for actual sCT content in each powder. The mass median aerodynamic diameter (MMAD) of the powders was also derived, defined as the particle size at the $50 \%$ cumulative fraction versus effective cut-off diameter.

\section{In vivo absorption of sCT-CS-NPs spray dried powders}

The animal studies were performed using 7-8 weeks bred, male Sprague Dawley rats weighing 200-250 g. The rats were randomly divided into groups (six rats in each group) and fasted for 24 hours prior to the study. The rats were allowed free access to water. The rats were anesthetized by intraperitoneal injection of urethane, and restrained in a supine position. Anesthesia was maintained with additional dose of sodium pentobarbital as needed throughout the experiment. The trachea was exposed and a PE-240 polyethylene tubing was inserted through a tracheal incision according to the method of Enna and Schanker ${ }^{25}$ and Kobayashi et al. ${ }^{26}$ The sample was administered to rat pulmonary using dry powder insufflators (Penn Century Inc, Wyndmoor, PA, USA). The powder administration was made by insufflation of $3 \mathrm{~mL}$ of air contained in the syringe. The insufflator was weighed before and after powder filling and after administration to determine the actual amount of sample emitted and aerosolized into the lung. The PE-10 polyethylene tubing were cannulated to the right jugular vein of the rats for blood sampling. Rats received samples equivalent to sCT of 20 IU/kg with each treatment. Group 1 rats were administered a single intratracheal dose of native sCT; Group 2 rats were administered a single intratracheal dose of sCT-CS-NPs; Group 3 rats were administered a single intratracheal dose of sCT-CS-NPs spray dried powders; Group 4 rats were administered a single intratracheal dose of unloaded CS-NPs spray dried powder, employed as blank samples, and Group 5 rats were administered a single dose of subcutaneous injection $\left(\right.$ Miacalcin $\left.{ }^{\circledR}\right)$. The animal experiment reported here was reviewed and approved by the Institutional Animal Care and Use Committee (IACUC) of Chulalongkorn University (Animal Use Protocol No 12-33-009) and conducted according to the guidelines documented in Ethical Principles and Guidelines for the Use of Animals for Scientific Purposes edited by the National Research Council of Thailand.

Blood samples of $200 \mu \mathrm{L}$ were collected at predetermined time intervals after administration and heparin solution as an anticoagulant was injected (1,000 unit/body) from the PE-10 tubing in advance. The blood samples were centrifuged at $8,000 \mathrm{rpm}$ for 15 minutes and kept at $-20^{\circ} \mathrm{C}$ until analysis. sCT levels were determined using the ELISA kit. The plasma concentrations versus time data were plotted and the various pharmacokinetic parameters, maximum plasma concentration $\left(\mathrm{C}_{\max }\right)$, time to reach maximum concentration $\left(\mathrm{T}_{\max }\right)$, and area under the curve from time zero to last time point of the experiment $\left(\mathrm{AUC}_{0-\mathrm{t}}\right)$ were estimated. The relative bioavailability $\left(\mathrm{F}_{\text {rel }}\right)$ for each formulation was calculated as:

$$
\mathrm{F}_{\text {rel }}=\frac{\mathrm{AUC}_{\text {sample }}}{\mathrm{AUC}_{\text {native } \mathrm{sCT}}}
$$

\section{Statistical analysis}

All experiments and analyses were performed in triplicate and the data were compared by one-way analysis of variance (ANOVA) and Scheffe's method tests all using the SPSS version 17 software (SPSS Inc., Chicago, IL, USA). A $P$-value $<0.05$ was considered statistically significant in all cases.

\section{Results and discussion Preparation of sCT-CS-NPs spray dried powders}

sCT-CS-NPs with particle size about $200 \mathrm{~nm}$ were formed spontaneously when $\mathrm{sCT}$ in TPP solution was added 
to CS solution. To obtain stable dry powder formulation with appropriate characteristics for inhalation, the sCT-CS-NPs were co-spray dried with mannitol as the carrier, resulting in sCT-CS-NPs mannitol based microparticles. The effects of mannitol concentration and inlet air temperature of spray drying process were investigated. The spray dried powder yields considerably varied between $38 \%$ to $68 \%$ as shown in Table 1. An increase in mannitol proportions resulted in an increase in process yields. Low spray dried powder yield might be a reflection of cohesive particles causing an adhesion of the powder to the wall of the spray drier. The mean particle size of spray dried powder was less than $5 \mu \mathrm{m}$ when using inlet temperature at $130^{\circ} \mathrm{C}$ and $150^{\circ} \mathrm{C}$. The higher inlet air temperature improved the process yields and gave the smaller size of spray dried powders. Also, a decrease in the content of mannitol was likely to give smaller size particles. Span measures the width of the particle size distribution. A smaller span value indicates a narrower particle size distribution of the powders. The span values of spray dried powder were apparently influenced by both mannitol content and inlet air temperature. An increase of inlet air temperature resulted in a decrease in span value. Span value was increased when increasing mannitol content. Chew and Chan reported that the span value would affect the aerosol performance of inhalation powder. Powders with a greater span value have produced a lower amount of fine particles generated in the aerosol cloud. ${ }^{27}$

The mannitol concentration and inlet air temperature clearly influenced the morphology of sCT-CS-NPs spray dried powders. As shown in Figure 1, dry powders were composed of a well-defined, smooth surface with a pitted appearance of microparticle aggregates. As can be seen, the particle morphology was dependent on the formulation composition and inlet air temperature; the particles formed were diverse in shape and size, with small primary particles that aggregated into clusters.

\section{Powder densities and estimated aerodynamic properties}

The true density, tapped density and CI of sCT-CS-NPs spray dried powders are listed in Table 2. True density varied between 1.45 and $1.59 \mathrm{~g} / \mathrm{cm}^{3}$ and tapped densities were relatively low, ranging between 0.15 and $0.36 \mathrm{~g} / \mathrm{cm}^{3}$ which rendered aerodynamic diameters of 2.5-4.7 $\mu \mathrm{m}$. As the size was appropriate for pulmonary administration, the spray dried powder would be able to carry the entrapped nanoparticles to the targeting site. ${ }^{28}$ A critical factor affecting dry powder inhalation performance is powder flowability. The CI value gives an indication of powder flow properties. An increase in CI value is proportional to the adhesion and friction property of the powder. A value less than $25 \%$ indicates a fluid flowing powder, whereas a value greater than $25 \%$ indicates cohesive powder characteristic that shows the poor flowability. ${ }^{29}$ The CI values of spray dried powders ranged from $18.2 \%$ to $27.9 \%$. Most of spray dried powders had CI values lower than $25 \%$, indicating a fluidity powder. Formulation F1 showed the highest CI value indicating a cohesive powder which would exhibit poor flow characteristics, while formulation F9 possessed the lowest CI value, hence the higher fluidity property. The data indicated that the lower mannitol concentration gave greater flowability of powder. Better flowability suggested better powder dispersibility, hence optimal aerosolization property. ${ }^{30}$

\section{SDS-PAGE analysis of sCT-CS-NPs spray dried powders}

The integrity of encapsulated SCT in spray dried powders, prepared using different NPs/M ratios and inlet air

Table I Effect of mannitol concentration and inlet air temperature on percentage yield and particle size of spray dried powders $($ mean $\pm S D, n=3)$

\begin{tabular}{llllll}
\hline Formulation & Mannitol (\%) & $\begin{array}{l}\text { Inlet air } \\
\text { temperature }\left({ }^{\circ} \mathbf{C}\right)\end{array}$ & $\begin{array}{l}\text { Spray dried } \\
\text { powders yield (\%) }\end{array}$ & $\begin{array}{l}\text { Particle sizes } \\
\mathbf{D}_{(0.5)}(\mu \mathrm{m})\end{array}$ \\
\hline FI & 90 & 110 & 46 & $5.70 \pm 1.53$ & $3.42 \pm 0.11$ \\
F2 & 110 & 41 & $5.42 \pm 2.34$ & $3.33 \pm 0.19$ \\
F3 & 80 & 110 & 38 & $5.01 \pm 1.54$ & $3.01 \pm 0.11$ \\
F4 & 70 & 130 & 57 & $4.67 \pm 2.12$ & $2.74 \pm 0.19$ \\
F5 & 90 & 130 & 48 & $4.03 \pm 1.34$ & $2.55 \pm 0.18$ \\
F6 & 80 & 130 & 42 & $3.89 \pm 1.48$ & $2.10 \pm 0.20$ \\
F7 & 70 & 150 & 68 & $4.04 \pm 1.47$ & $2.22 \pm 0.22$ \\
F8 & 90 & 150 & 57 & $3.86 \pm 2.05$ & $1.88 \pm 0.16$ \\
F9 & 80 & 150 & 51 & $3.74 \pm 1.21$ & $1.99 \pm 0.17$ \\
\hline
\end{tabular}

Abbreviation: SD, standard deviation. 

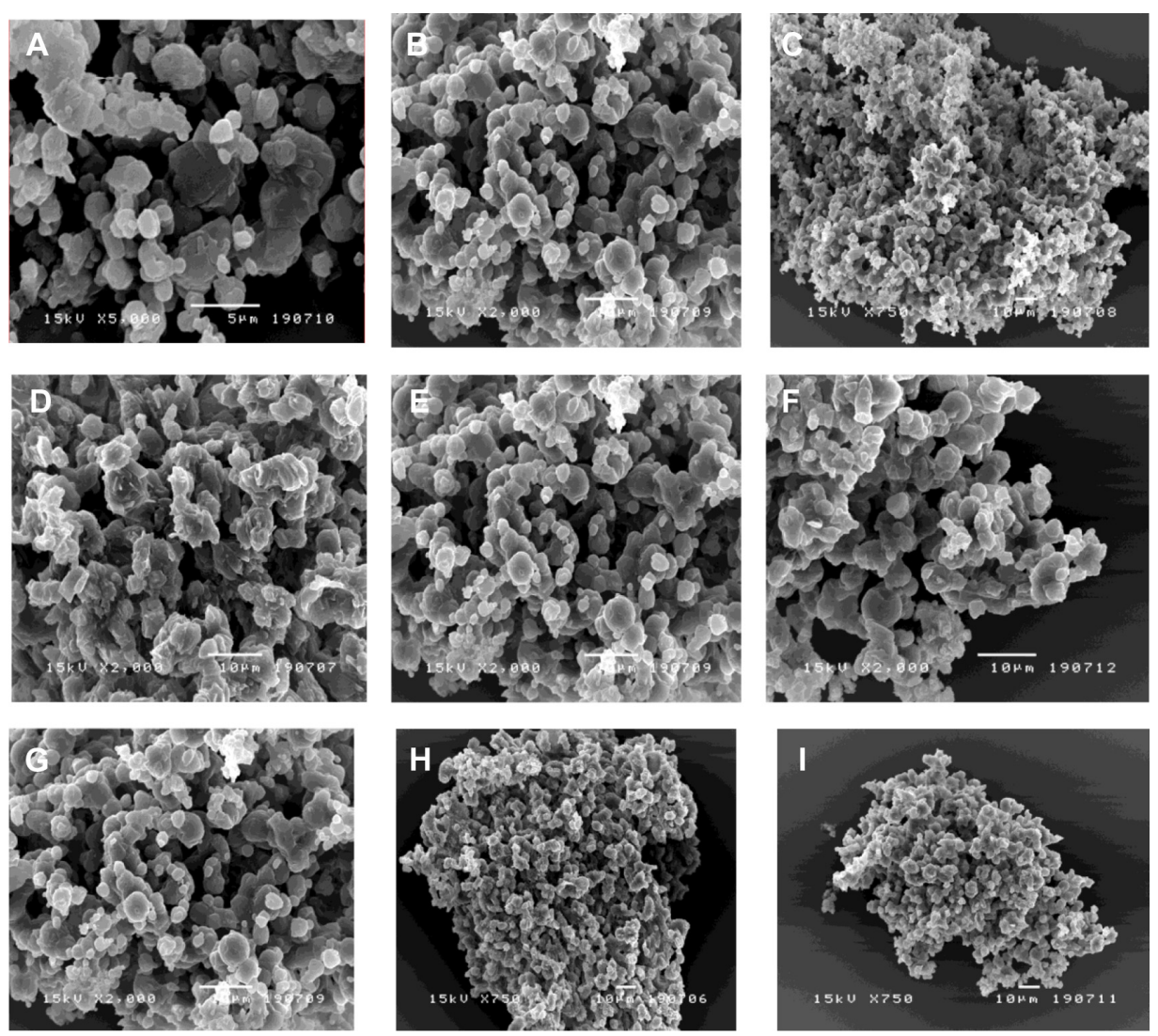

Figure I Scanning electron micrographs of sCT-CS-NPs spray dried powders using different nanoparticles/mannitol ratios (NPs/M) and inlet temperatures. (A) NPs $/$ M $=10 / 90$, (B) $\mathrm{NPs} / \mathrm{M}=20 / 80$, (C) NPs/M = 30/70 all prepared at $110^{\circ} \mathrm{C}$, (D) NPs $/ \mathrm{M}=10 / 90$, (E) NPs/M = 20/80, (F) NPs/M = 30/70 all prepared at $130^{\circ} \mathrm{C}$ and (G) NPs/M=10/90, (H), NPs $/ \mathrm{M}=20 / 80$, (I) NPs $/ \mathrm{M}$ all prepared at $150^{\circ} \mathrm{C}$.

Abbreviations: M, mannitol; sCT-CS-NPs, salmon calcitonin loaded chitosan nanoparticles.

temperatures, was investigated by SDS-PAGE. Figure 2A displays SDS-PAGE analysis of sCT-CS-NPs spray dried powders of 30:70 NPs:mannitol when prepared using different inlet air temperatures. Unprocessed sCT was also run as a control (L2). It appeared that the high inlet air temperature of $150^{\circ} \mathrm{C}$ gave the band of higher molecular weight region (L5) when compared to that prepared at $110^{\circ} \mathrm{C}$ and $130^{\circ} \mathrm{C}$, which moved downwards on the electrophoretic gels (L3 and L4) to a distance comparable to the control (L2). These results suggest that encapsulated $\mathrm{sCT}$ was aggregated when spray drying was performed under high thermal stress.

As illustrated in Figure 2B, all bands of sCT recovered from sCT-CS-NPs spray dried powders containing different proportions of mannitol when spray dried at an inlet temperature of

Table 2 Densities and aerodynamic diameter of dry powders prepared using different mannitol concentrations and inlet air temperatures $($ mean $\pm \mathrm{SD}, \mathrm{n}=3$ )

\begin{tabular}{|c|c|c|c|c|c|c|}
\hline Formulation & $\begin{array}{l}\text { Mannitol concentrations } \\
(\% w / w)\end{array}$ & $\begin{array}{l}\text { Inlet air } \\
\text { temperatures }\left({ }^{\circ} \mathrm{C}\right)\end{array}$ & $\begin{array}{l}\text { True density } \\
\left(\mathrm{g} / \mathrm{cm}^{3}\right)\end{array}$ & $\begin{array}{l}\text { Tapped density } \\
\left(\mathrm{g} / \mathrm{cm}^{3}\right)\end{array}$ & $\mathrm{Cl}(\%)$ & $\mathrm{d}_{\mathrm{aer}}(\mu \mathrm{m})$ \\
\hline$\overline{\mathrm{FI}}$ & 90 & 110 & $1.45 \pm 0.02$ & $0.36 \pm 0.05$ & $27.88 \pm 0.12$ & $4.70 \pm 0.07$ \\
\hline F2 & 80 & 110 & $1.46 \pm 0.04$ & $0.32 \pm 0.02$ & $25.71 \pm 0.08$ & $4.12 \pm 0.04$ \\
\hline F3 & 70 & 110 & $1.48 \pm 0.03$ & $0.28 \pm 0.06$ & $20.56 \pm 0.10$ & $3.81 \pm 0.10$ \\
\hline $\mathrm{F} 4$ & 90 & 130 & $1.49 \pm 0.06$ & $0.35 \pm 0.03$ & $24.85 \pm 0.06$ & $4.37 \pm 0.09$ \\
\hline F5 & 80 & 130 & $1.55 \pm 0.05$ & $0.28 \pm 0.01$ & $23.35 \pm 0.08$ & $3.83 \pm 0.13$ \\
\hline F6 & 70 & 130 & $1.59 \pm 0.03$ & $0.25 \pm 0.04$ & $19.58 \pm 0.13$ & $2.89 \pm 0.06$ \\
\hline F7 & 90 & 150 & $1.57 \pm 0.07$ & $0.30 \pm 0.05$ & $22.67 \pm 0.11$ & $4.04 \pm 0.03$ \\
\hline F8 & 80 & 150 & $1.59 \pm 0.02$ & $0.23 \pm 0.07$ & $20.57 \pm 0.07$ & $3.76 \pm 0.11$ \\
\hline F9 & 70 & 150 & $1.58 \pm 0.01$ & $0.15 \pm 0.02$ & $18.15 \pm 0.02$ & $2.51 \pm 0.07$ \\
\hline
\end{tabular}

Abbreviations: $\mathrm{Cl}$, Carr index; $\mathrm{d}_{\text {aer }}$, aerodynamic diameter; $\mathrm{SD}$, standard deviation; $\mathrm{w}$, weight. 


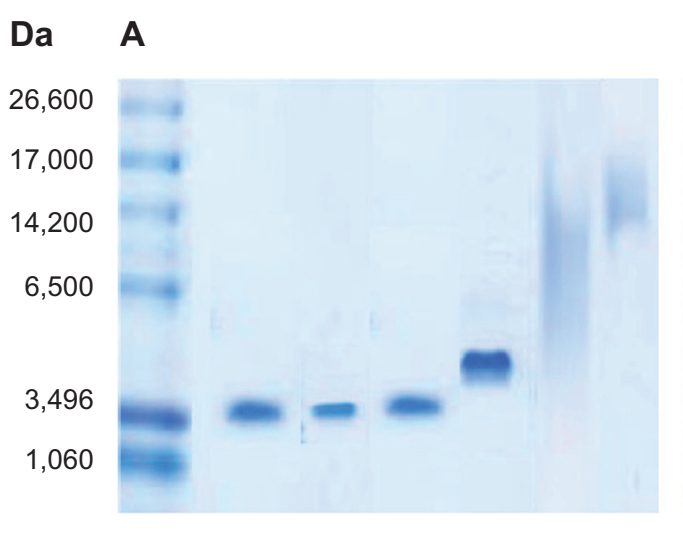

L1 $\quad$ L2 $\quad$ L3 $\quad$ L4 $\quad$ L5 $\quad$ L6 $\quad$ L7
B

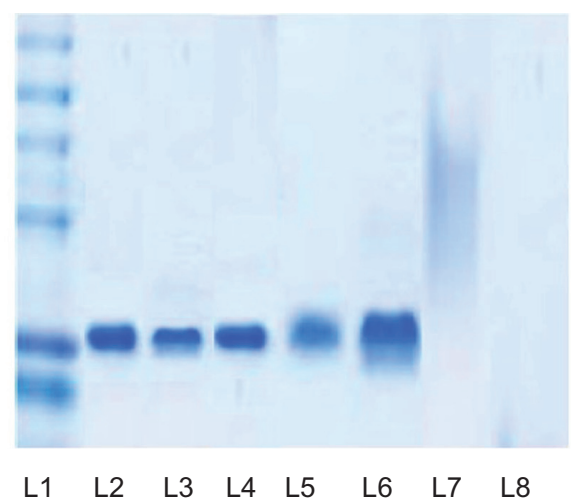

Figure 2 (A) SDS-PAGE analysis of LI: sCT standard marker, L2: unprocessed sCT $(0.1 \mu \mathrm{g} / \mathrm{mL})$, L3, L4, and L5: sCT recovered from sCT-CS-NPs spray dried powders $(\mathrm{NPs} / \mathrm{M}=30 / 70)$, prepared at the inlet temperatures of $110^{\circ} \mathrm{C}, 130^{\circ} \mathrm{C}$, and $150^{\circ} \mathrm{C}$, respectively, L6: blank spray dried powder, and L7: sample buffer. (B) SDS-PAGE analysis of LI: sCT standard marker, L2 and L3: unprocessed sCT $(0.2$ and $0.1 \mu \mathrm{g} / \mathrm{mL}), \mathrm{L} 4, \mathrm{~L} 5$, and L6: $\mathrm{sCT}$ recovered from sCT-CS-NPs spray dried powders with NPs/M = $10 / 90$, $\mathrm{NPs} / \mathrm{M}=20 / 80$, and NPs/M = 30/70, respectively, when prepared using an inlet temperature of I30 ${ }^{\circ} \mathrm{C}$, L7: blank spray dried powder and L8: sample buffer.

Abbreviations: CS, chitosan; M, mannitol; NPs, nanoparticles; sCT, salmon calcitonin loaded; SDS-PAGE, sodium dodecyl sulfate polyacrylamide gel electrophoresis.

$130^{\circ} \mathrm{C}$ (L4-L6) moved downwards on the electrophoretic gel to a distance comparable to the control (L2 and L3). No band was observed in either the higher or lower molecular weight regions, suggesting that neither aggregate formation nor peptide backbone clipping occurred. It was therefore conceivable that the varied concentrations of mannitol used in this study did not affect the sCT integrity. The smear appeared on the lanes of sCT loaded CS-NPs spray dried powders is believed to be the staining of chitosan, since it was also found on the lane of blank chitosan microparticles (L7). From SDS-PAGE analysis, spray drying at an inlet air temperature at $130^{\circ} \mathrm{C}$ could avoid deterioration of the loaded protein.

\section{Conformational change assay by circular dichroism (CD)}

The secondary structural conformation of sCT encapsulated in chitosan nanoparticles when co-spray dried with mannitol carrier was studied with CD spectroscopy. The CD spectroscopic analysis was performed in the "far-UV" region (190-240 nm). The CD spectra of sCT-CS-NPs spray dried powders composed of various amounts of mannitol prepared at the inlet air temperature of $130^{\circ} \mathrm{C}$ in comparison with native $\mathrm{SCT}$ and SCT-CS-NPs are displayed in Figure 3. The CD spectra showed a variation in ellipticity, despite equal protein concentration. The native $\mathrm{SCT}$ gave

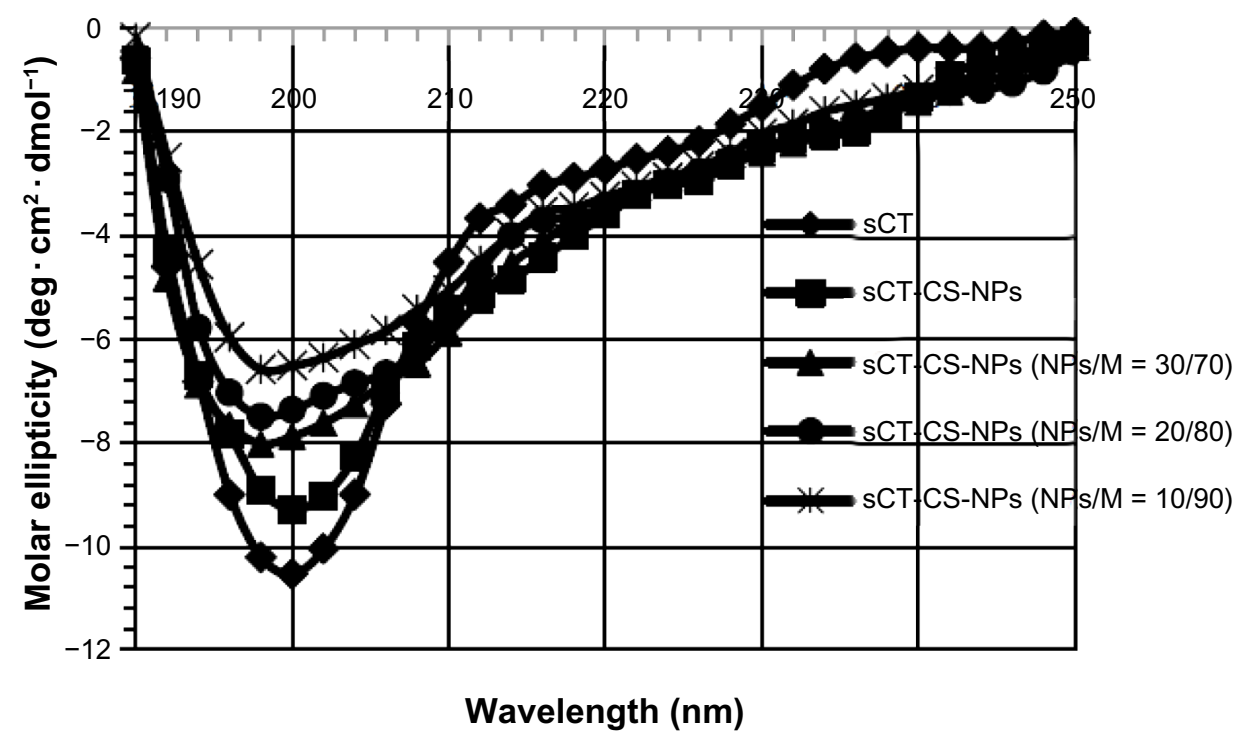

Figure $3 \mathrm{sCT}$ circular dichroism spectra in acetate buffer $\mathrm{pH} 4.4$ of: $(\bullet)$ native $\mathrm{sCT}$, ( $\mathbf{\square}) \mathrm{sCT}$-CS-NPs compared to sCT-CS-NPs spray dried powders containing different sCT loaded CS-NPs/mannitol ratios of $(\mathbf{\Delta}) \mathrm{NPs} / \mathrm{M}=30 / 70 ;(\bullet) \mathrm{NPs} / \mathrm{M}=20 / 80$; and $(\mathrm{X}) \mathrm{NPs} / \mathrm{M}=10 / 90$ when using an inlet air temperature of $130^{\circ} \mathrm{C}$.

Abbreviations: CS, chitosan; M, mannitol; NPs, nanoparticles; sCT, salmon calcitonin loaded. 


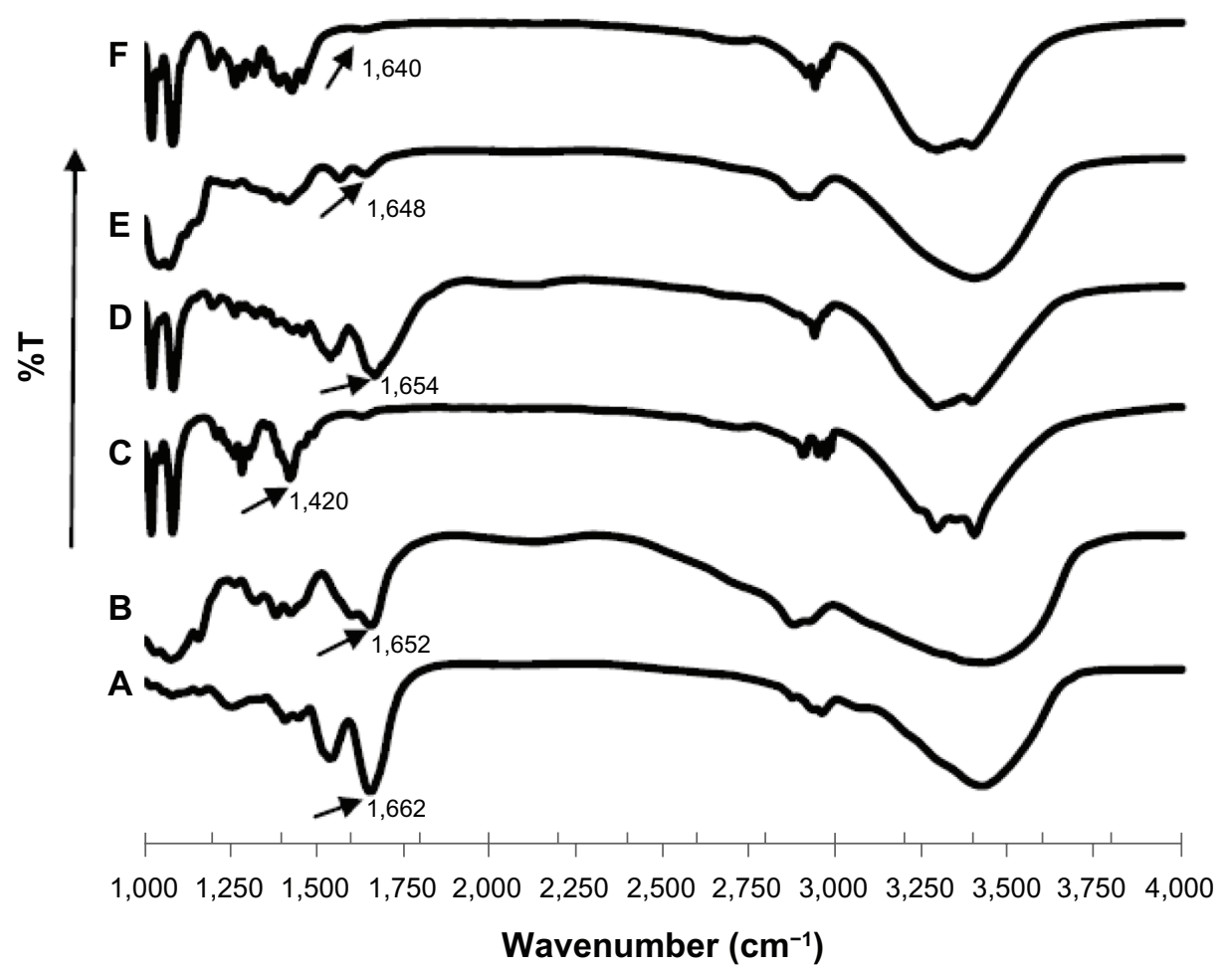

Figure 4 FTIR spectra of: $(\mathbf{A})$ native $\mathrm{sCT},(\mathbf{B})$ chitosan, $(\mathbf{C})$ mannitol, and sCT-CS-NPs spray dried powders of $(\mathbf{D}) \mathrm{NPs} / \mathrm{M}=30 / 70,(\mathrm{E}) \mathrm{NPs} / \mathrm{M}=20 / 80$, (F) NPs/M= I0/90 prepared using an inlet temperature of $130^{\circ} \mathrm{C}$.

Abbreviations: CS, chitosan; FTIR, Fourier transform infrared; M, mannitol; NPs, nanoparticles; sCT, salmon calcitonin loaded; T, transmittance.

negative minimum band at $200 \mathrm{~nm}$, while a molar ellipticity of sCT-CS-NPs decreased without significant shift of the minimum wavelength suggesting that chitosan affected the structure integrity of $\mathrm{sCT}$. The result was corresponding with a previous report. ${ }^{10}$ Subsequently, when spray dried with mannitol, a further decrease in molar ellipticity with a slight shift of minimum found when comparing with native $\mathrm{SCT}$ and SCT-CS-NPs. Increasing mannitol concentrations exerted more effect on molar ellipticity and a shift of minimum to 198, 195, and $189 \mathrm{~nm}$ for mannitol content of 70, 80, and $90 \%$, respectively. These results indicate that a change in secondary structure of $\mathrm{SCT}$ could occur when co-spray dried with mannitol.

\section{Conformational changes assay by Fourier transform infrared (FTIR) spectroscopy}

FTIR spectroscopic analysis is one of the techniques that can be applied for secondary structure characterization of peptides and proteins. ${ }^{9} 10$ The structural changes can be monitored in the amide I, II, or III region, where the amide I band between 1,600 and $1,700 \mathrm{~cm}^{-1}$ is the most intense absorbance band for all the investigated proteins and peptides, being mainly associated with the $\mathrm{C}=\mathrm{O}$ stretching vibration of amide and directly related to the backbone conformation. As shown in Figure 4A, native SCT showed a prominent absorption band at $1662 \mathrm{~cm}^{-1}$ in the FTIR spectrum, an indication of $\alpha$-helical content. sCTCS-NPs spray dried powders of 30/70 NPs/mannitol exhibited a slight spectral change of amide I located at $1,654 \mathrm{~cm}^{-1}$ compared to the FTIR spectrum of the native sCT. However, the amide I band of sCT-CS-NPs spray dried powders with NPs/mannitol ratio of $20 / 80$ and 10/90 shifted to 1,648 and $1,640 \mathrm{~cm}^{-1}$, respectively. A shift to lower wavenumbers of the SCT amide I band in FTIR spectra was probably attributed to character of random coil structure formation. ${ }^{31}$ The results suggested that an increasing level of mannitol content would induce a conformation change of SCT.


Figure $\mathbf{5}$ TEM of $(\mathbf{A})$ freshly prepared nanoparticles and $(\mathbf{B})$ recovered nanoparticles from spray dried powder (NPs/M $=30 / 70)$ prepared at an inlet temperature of $130^{\circ} \mathrm{C}$. Abbreviations: M, mannitol; NPs, nanoparticles; TEM, transmission electron microscopy. 
Table 3 Size and zeta potential of freshly prepared sCT-CS-NPs and nanoparticles recovered from spray dried powders (mean \pm $\mathrm{SD}, \mathrm{n}=3$ )

\begin{tabular}{llll}
\hline Formulation & $\begin{array}{l}\text { Size } \\
(\mathbf{n m})\end{array}$ & $\begin{array}{l}\text { Polydispersity } \\
\text { index (PDI) }\end{array}$ & $\begin{array}{l}\text { Zeta potential } \\
(\mathrm{mV})\end{array}$ \\
\hline $\begin{array}{l}\text { Freshly prepared } \\
\text { sCT-CS-NPs }\end{array}$ & $210 \pm 0.12$ & $0.109 \pm 0.14$ & $+24 \pm 0.08$ \\
$\begin{array}{l}\text { sCT-CS-NPs spray } \\
\text { dried powders }\end{array}$ & $215 \pm 0.15$ & $0.115 \pm 0.11$ & $+28 \pm 0.16$ \\
\hline
\end{tabular}

Abbreviations: SCT-CS-NPs, salmon calcitonin loaded chitosan nanoparticles; SD, standard deviation.

The addition of mannitol at high concentrations influenced the aggregation of $\mathrm{SCT}$, but relevant alterations in the secondary structure of the protein were not obvious. Apparently, aggregation was not the consequence of changes in the secondary structure that could be picked up by FTIR. The formation of aggregates may be due to changes in very small sections or sequences of the sCT molecule that could not be detected by FTIR. It was also possible that aggregation was not related to changes in the secondary protein structure. $^{32}$

Based on SDS-PAGE, CD spectroscopy, and FTIR spectroscopy analysis, the integrity of $\mathrm{sCT}$ in spray dried powders was likely to be affected by high content of mannitol and inlet temperature. However, the previous report concerning the effect of spray drying on the structural change of protein gave divergent results. Dehydration of protein can lead to either an irreversible destruction of the secondary structure or that the structural changes can be reversible upon rehydration. ${ }^{32}$ Maury et al reported an increase of protein (immunoglobulin $\mathrm{G}$ ) aggregation after spray drying but reverted to the native structure on redissolution of the powder. ${ }^{33}$ The study by Schüle et al showed that the aggregation of antibody after the spray drying process are not correlated with significant change of the protein secondary structure. ${ }^{32}$ An investigation by Chan et al showed no sCT aggregation occurred when co-spray drying with mannitol. ${ }^{9}$ In this work, SDS-PAGE study showed the aggregation of $\mathrm{sCT}$ when using an inlet temperature of $150^{\circ} \mathrm{C}$. CD spectroscopy and FTIR spectroscopy analysis for $\mathrm{sCT}$ in spray dried powders demonstrated the potential induction of conformation change of secondary structure by high mannitol content. In order to preserve protein integrity in sCT-CS-NPs spray dried powders, NPs/mannitol ratio of 30/70 and a spray drying inlet temperature of $130^{\circ} \mathrm{C}$ were, therefore, employed to prepare sCT-CS-NPs spray dried powders for pulmonary absorption study in animals.

\section{Nanoparticles recovery from spray dried powders in aqueous medium}

It was observed that after incubating the spray dried powders of 30/70 NPs/mannitol prepared using inlet temperature of $130^{\circ} \mathrm{C}$ in the aqueous medium under low stirring rate, mannitol was dissolved resulting in a cloudy solution. Figure 5 displays the TEM microphotographs of the recovered nanoparticles compared to the freshly prepared formulation. The recovered nanoparticles of spray dried powders had a similar appearance to that found in the freshly prepared formulation. Table 3 presents size, polydispersity index (PDI), and zeta potential of the nanoparticles recovered from spray dried powders and fresh preparation. The size of freshly prepared

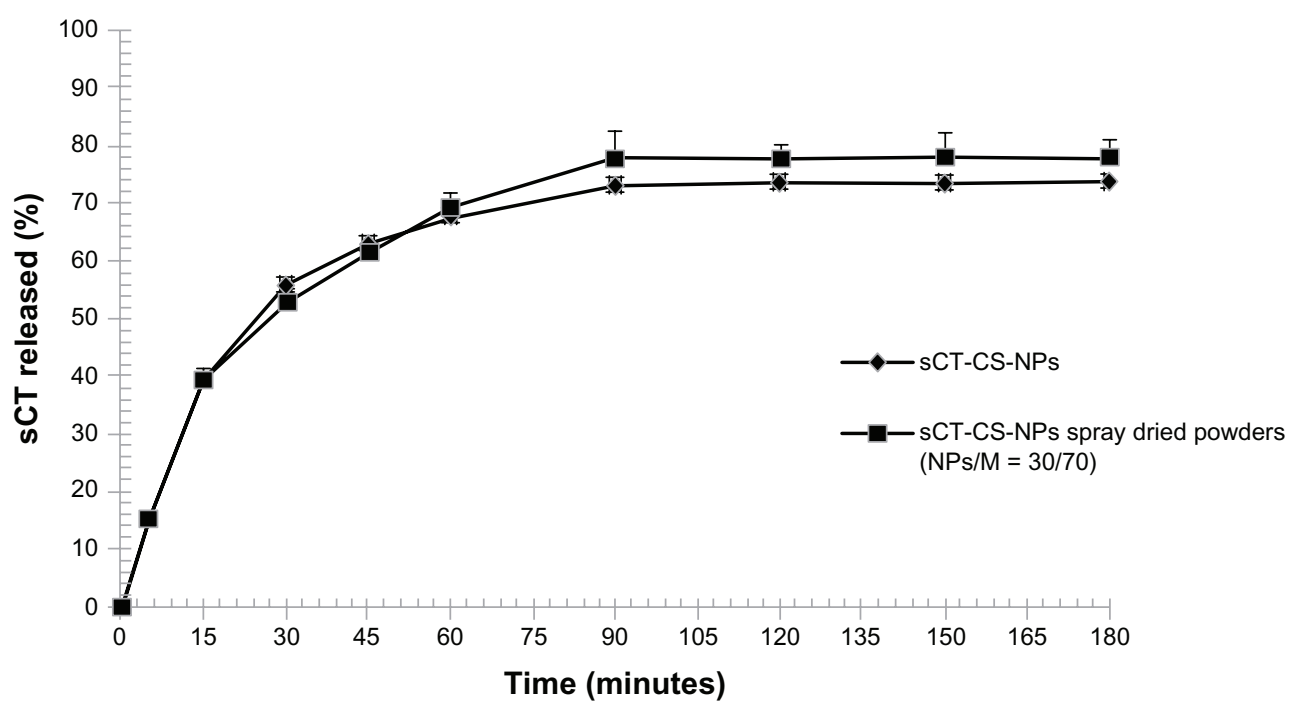

Figure 6 In vitro release profile of sCT-CS-NPs and sCT-CS-NPs spray dried powders (NPs/M=30/70) prepared using an inlet air temperature of $130^{\circ} \mathrm{C}$. Abbreviations: M, mannitol; sCT-CS-NPs, salmon calcitonin loaded chitosan nanoparticles. 
Table 4 Mass median aerodynamic diameter, fine particle fraction, emitted dose and dispersibility of sCT-CS-NPs spray dried powders determined with $\mathrm{ACl}($ mean $\pm \mathrm{SD}, \mathrm{n}=3$ )

\begin{tabular}{lllll}
\hline Formulation & $\begin{array}{l}\text { MMAD } \\
(\mu \mathrm{m})\end{array}$ & $\begin{array}{l}\text { FPF } \\
\mathbf{( \% )}\end{array}$ & $\begin{array}{l}\text { ED } \\
(\%)\end{array}$ & $\begin{array}{l}\text { Dispersibility } \\
(\%)\end{array}$ \\
\hline sCT-CS-NPs powder & 3.45 & 18.67 & 22.43 & 48.71 \\
sCT-CS-NPs spray dried & 2.72 & 63.50 & 71.17 & 78.58 \\
powders (NPs/M = 30/70) & & & & \\
\hline
\end{tabular}

Abbreviations: $\mathrm{ACl}$, Andersen Cascade Impactor; ED, emitted dose; FPF, fine particle fraction; MMAD, mass median aerodynamic diameter; M, mannitol; sCTCS-NPs, salmon calcitonin loaded chitosan nanoparticles; SD, standard deviation.

nanoparticles and recovered nanoparticles were apparently unchanged, being $210 \pm 0.12$ and $215 \pm 0.15 \mathrm{~nm}$, respectively. Both samples showed similar PDI values, indicating a similar size distribution. Also, the zeta potential of the nanoparticles was not altered after processing with the presence of mannitol. It was, therefore, hypothesized that when the spray dried powders reached the deep lung, the soluble component (mannitol) in the microparticles was dissolved in the lung fluid and released the nanoparticles.

\section{In vitro release studies of sCT-CS-NPs spray dried powders}

sCT-CS-NPs spray dried powders were subjected to in vitro release test at $37^{\circ} \mathrm{C}$ in $\mathrm{pH} 7.4$ phosphate buffer compared to sCT-CS-NPs before spray drying. The results are illustrated as a plot of percentage of sCT released against time (Figure 6). Initially, about $40 \%$ of $\mathrm{sCT}$ was burst released during 15 minutes and reach the plateau within 90 minutes. Over $70 \%$ of sCT was completely released at 90 minutes and no further release was found. The initial burst release was caused by those protein molecules encapsulated close to particle surface, which easily diffused out at initial incubation time. ${ }^{34}$ There might be weak interaction between CS-NPs and $\mathrm{sCT}$, allowing the $\mathrm{sCT}$ release from the nanoparticles by a dissociation mechanism. ${ }^{19}$

\section{Evaluation of sCT-CS-NPs spray dried powders aerosolization}

The aerodynamic properties of the sCT-CS-NPs spray dried powders prepared at an inlet air temperature of $130^{\circ} \mathrm{C}$ were measured by inertial impaction and compared to sCT-CSNPs powders. sCT-CS-NPs powders were prepared without mannitol and employed in this study for comparison. By determination of the particle distribution on the different impactor stages, the aerodynamic properties of the generated aerosols could be calculated. The deposition data obtained from aerosolization of the sCT-CS-NPs spray dried powders are summarized in Table 4. sCT-CS-NPs spray dried powders exhibited significantly higher deposition profiles compared to the sCT-CS-NPs powders without carrier. A significant increase in emitted dose percentage of the sCT from aerosolized powders containing mannitol indicated that the addition of mannitol could improve the aerosol properties. In addition, the sCT-CS-NPs with mannitol based spray dried powders gave a high fine particle fraction (FPF) expressed as a percentage of the total amount of $\mathrm{sCT}$ collected from the stage II of ACI, as well as the emitted dose (ED) and dispersibility characteristics. The higher in vitro deposition parameters of the $\mathrm{sCT}$ from aerosolized spray dried powders

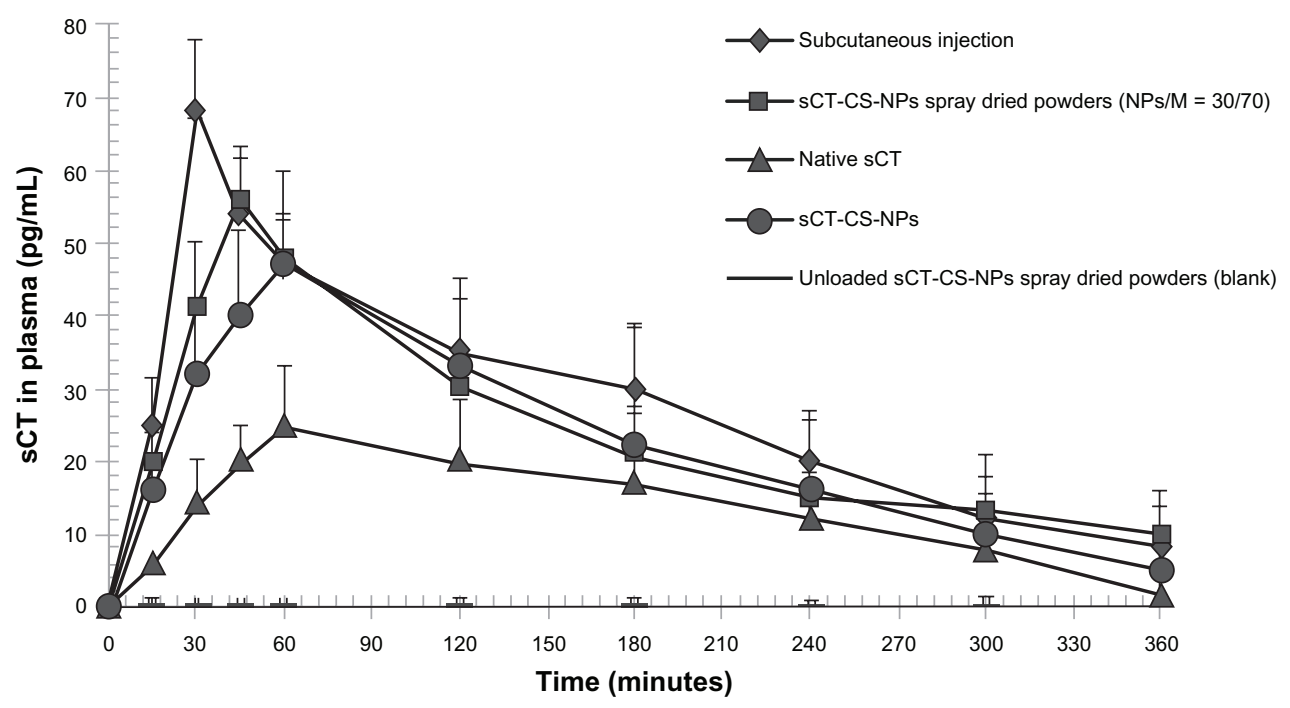

Figure 7 Plasma sCT concentration versus time profiles following intratracheal administration of native sCT, sCT-CS-NPs, sCT-CS-NPs spray dried powders and CS-NPs spray dried powders (blank, without loading SCT) compared to subcutaneous administration in rats; mean $\pm S D(n=6)$. Abbreviations: CS, chitosan; M, mannitol; NPs, nanoparticles; sCT, salmon calcitonin loaded; SD, standard deviation. 
with mannitol might be related to the surface properties of the particles. It is believed that Van der Waals force could contribute to the strong adhesion of smooth surface particles. The effect of surface roughness on aerosolized properties of drug was also reported by Chew and Chan. ${ }^{35}$

\section{In vivo absorption of sCT-CS-NPs spray dried powders}

The sCT-CS-NPs spray dried powders composed of 30/70 NPs/mannitol, prepared at an inlet air temperature of $130^{\circ} \mathrm{C}$, showed the appropriate aerodynamic properties and protein stability, so it was selected for in vivo study. The intratracheal administration of sCT-CS-NPs spray dried powders in rats was performed to evaluate $\mathrm{sCT}$ absorption. The serum sCT concentrations versus time profiles following insufflations of the sCT-CS-NPs spray dried powders, sCT-CS-NPs powders, native sCT, and CS-NPs spray dried powders (blank) are presented in Figure 7. Pharmacokinetic studies were included to assess potential differences in the pulmonary absorption, maximal plasma concentration $\left(\mathrm{C}_{\max }\right), \mathrm{T}_{\max }$, area under the curve $\left(\mathrm{AUC}_{0-360}\right)$, and the relative bioavailability $\left(\mathrm{F}_{\text {rel }}\right)$. Pharmacokinetic parameters are presented in Table 5. After subcutaneous administration, plasma $\mathrm{SCT}$ concentration increased rapidly and reached a $\mathrm{C}_{\max }$ of $68 \mathrm{pg} / \mathrm{mL}$ in 30 minutes $\left(\mathrm{T}_{\max }\right)$. sCT-CS-NPs spray dried powders gave a $\mathrm{C}_{\max }$ of $56 \mathrm{pg} / \mathrm{mL}$ in 45 minutes; there was a significant difference between sCT-CS-NPs spray dried powders compared to the native sCT $(P<0.05)$. Calculated $\mathrm{F}_{\text {rel }}$ indicated greater pulmonary absorption of $\mathrm{sCT}$ when it was encapsulated in nanoparticles. sCT-CS-NPs spray dried powders provided lower bioavailability than that of subcutaneous injection but produced a higher bioavailability than sCT-CS-NPs alone and native sCT powder.

Table 5 Pharmacokinetic parameters (mean \pm SD, $\mathrm{n}=6$ )

\begin{tabular}{|c|c|c|c|c|}
\hline Sample & $\begin{array}{l}C_{\max } \\
\left(\mathrm{pg} \cdot \mathrm{mL}^{-1}\right)\end{array}$ & $\begin{array}{l}T_{\max } \\
(\min )\end{array}$ & $\begin{array}{l}\text { AUC }_{0-360} \\
\left(\mathrm{~min} \cdot \mathrm{pg} \cdot \mathrm{mL}^{-1}\right)\end{array}$ & $\mathbf{F}_{\text {rel }}$ \\
\hline $\begin{array}{l}\text { Subcutaneous } \\
\text { injection (Miacalcin }{ }^{\circledR} \text { ) }\end{array}$ & $68 \pm 5.14$ & 30 & $10,014.60 \pm 125.47$ & 2.00 \\
\hline Native sCT & $25 \pm 3.03$ & 60 & $5,004.60 \pm 87.64$ & 1.00 \\
\hline sCT-CS-NPs & $47 \pm 4.45$ & 60 & $8,068.80 \pm 105.18$ & 1.61 \\
\hline $\begin{array}{l}\text { sCT-CS-NPs spray } \\
\text { dried powders } \\
(\mathrm{NPs} / \mathrm{M}=30 / 70)\end{array}$ & $56 \pm 4.56$ & 45 & $8,578.80 \pm 98.63$ & I.7| \\
\hline $\begin{array}{l}\text { CS-NPs spray dried } \\
\text { powders (blank, } \\
\text { without sCT loading) }\end{array}$ & $0.34 \pm 1.23$ & 360 & $0.697 \pm 24.38$ & 0.0083 \\
\hline
\end{tabular}

\section{Conclusion}

sCT loaded chitosan nanoparticles can be incorporated in microparticles by co-spray drying of nanoparticles with mannitol. The spray dried powders possessed appropriate aerodynamic properties for pulmonary delivery. Optimization of formulation and spray drying parameters was essential to maintain protein integrity. Following intratracheal administration to the rats, the quantitative analyses of plasmatic sCT and pharmacokinetic parameters obtained demonstrated that this system is able to deliver sCT, via the deep lung region, into systemic circulation. The results suggest that the designed SCT containing nanoparticles were released from spray dried microparticles upon exposure to lung fluid.

\section{Acknowledgments}

The authors are grateful to Dr Thongchai Sooksawate, Faculty of Pharmaceutical Sciences, Chulalongkorn University for advice and technical support on animal studies. Thanks to Dr Teerapol Srichana, Faculty of Pharmaceutical Sciences, Prince of Songkla University for technical advice and use of the Anderson Cascade Impactor. Technical support on SDS-PAGE analysis given by Dr Chirasak Kusonwiriyawong, Faculty of Pharmacy, Rangsit University is much appreciated.

\section{Disclosure}

The authors report no conflicts of interest in this work.

\section{References}

1. Siekmeier R, Scheuch G. Systemic treatment by inhalation of macromolecules - principles, problems, and examples. J Physiol Pharmacol. 2008;59 Suppl 6:53-79.

2. Patton JS. Mechanisms of macromolecule absorption by the lungs. $A d v$ Drug Deliv Rev. 1996;19:3-36.

3. Schneyer CR. Calcitonin and the treatment of osteoporosis. Md Med J. 1991;40(6):469-473

4. Harvey SC, Withrow CD. Hormones. In: Gennaro AR, Chase GD, Gibson MR, Granberg CB, Harvey SC, editors. Remington's Pharmaceutical Sciences. Pennsylvania: Mack Printing Company; 1985:951-1001

5. Ugwoke MI, Verbeke N, Kinget R. The biopharmaceutical aspects of nasal mucoadhesive drug delivery. J Pharm Pharmacol. 2001;53(1): 3-21.

6. Dombu CY, Betbeder D. Airway delivery of peptides and proteins using nanoparticles. Biomaterials. 2013;34(2):516-525.

7. Pires A, Fortuna A, Alves G, Falcão A. Intranasal drug delivery: how, why and what for? J Pharm Pharm Sci. 2009;12(3):288-311.

8. Lee WA, Ennis RD, Longenecker JP, Bengtsson P. The bioavailability of intranasal salmon calcitonin in healthy volunteers with and without a permeation enhancer. Pharm Res. 1994;11(5):747-750.

9. Chan HK, Clark AR, Feeley JC, et al. Physical stability of salmon calcitonin spray-dried powders for inhalation. J Pharm Sci. 2004;93(3):792-804.

10. Yang M, Velaga S, Yamamoto $H$, et al. Characterisation of salmon calcitonin in spray-dried powder for inhalation. Effect of chitosan. Int J Pharm. 2007;331(2):176-181. 
11. Azarmi S, Roa WH, Löbenberg R. Targeted delivery of nanoparticles for the treatment of lung diseases. Adv Drug Deliv Rev. 2008;60: 863-875.

12. Yang W, Peters JI, Williams RO. Inhaled nanoparticles - a current review. Int J Pharm. 2008;356(1-2):239-247.

13. Sham JO, Zhang Y, Finlay WH, Roa WH, Löbenberg R. Formulation and characterization of spray-dried powders containing nanoparticles for aerosol delivery to the lung. Int J Pharm. 2004;269(2):457-467.

14. Steckel H, Bolzen N. Alternative sugars as potential carriers for dry powder inhalations. Int J Pharm. 2004;270(1-2):297-306.

15. Tee SK, Marriott C, Zeng XM, Martin GP. The use of different sugars as fine and coarse carriers for aerosolised salbutamol sulphate. Int J Pharm. 2000;208(1-2):111-123.

16. Saint-Lorant G, Leterme P, Gayot A, Flament MP. Influence of carrier on the performance of dry powder inhalers. Int J Pharm. 2007;334(1-2): 85-91.

17. Glover W, Chan HK, Eberl S, Daviskas E, Verschuer J. Effect of particle size of dry powder mannitol on the lung deposition in healthy volunteers. Int J Pharm. 2008;349(1-2):314-322.

18. Grenha A, Seijo B, Remuñán-López C. Microencapsulated chitosan nanoparticles for lung protein delivery. Eur J Pharm Sci. 2005;25(4-5): 427-437.

19. Fernández-Urrusuno R, Calvo P, Remuñán-López C, Vila-Jato JL, Alonso MJ. Enhancement of nasal absorption of insulin using chitosan nanoparticles. Pharm Res. 1999;16(10):1576-1581.

20. Aydin Z, Akbuga J. Chitosan beads for the delivery of salmon calcitonin: Preparation and release characteristics. Int J Pharm. 1996;131: 101-103.

21. Calvo P, Remuñan-López C, Vila-Jato JL, Alonso MJ. Chitosan and chitosan/ethylene oxide-propylene oxide block copolymer nanoparticles as novel carriers for proteins and vaccines. Pharm Res. 1997;14(10): 1431-1436.

22. Illum L. Chitosan and its use as a pharmaceutical excipient. Pharm Res. 1998;15(9):1326-1331.

23. Issa MM, Köping-Höggård M, Artursson P. Chitosan and the mucosal delivery of biotechnology drugs. Drug Discov Today: Technologies. 2005;2(1):1-6.
24. Grenha A, Grainger CI, Dailey LA, et al. Chitosan nanoparticles are compatible with respiratory epithelial cells in vitro. Eur J Pharm Sci. 2007;31(2):73-84.

25. Enna SJ, Schanker LS. Absorption of saccharides and urea from the rat lung. Am J Physiol. 1972;222(2):409-414.

26. Kobayashi S, Kondo S, Juni K. Pulmonary delivery of salmon calcitonin dry powders containing absorption enhancers in rats. Pharm Res. 1996;13(1):80-83.

27. Chew NY, Chan HK. Effect of powder polydispersity on aerosol generation. J Pharm Pharm Sci. 2002;5(2):162-168.

28. Ungaro F, d'Angelo I, Miro A, La Rotonda MI, Quaglia F. Engineered PLGA nano- and micro-carriers for pulmonary delivery: challenges and promises. J Pharm Pharmacol. 2012;64(9):1217-1235.

29. de Villiers MM. Powder flow and compressibility. In: Ghosh TK, Jasti BR, editors. Theory and Practice of Contemporary Pharmaceutics. Boca Raton: CRC Press; 2005:298-299.

30. Learoyd TP, Burrows JL, French E, Seville PC. Chitosan-based spraydried respirable powders for sustained delivery of terbutaline sulfate. Eur J Pharm Biopharm. 2008;68(2):224-234.

31. Yang B, Jiang HL, Ding ZK, Zhang QK. Secondary structure in solution of an analog of salmon calcitonin: [Val(1), Ala(7)] sCT. Chinese Chemical Letters. 1999;10:555-558.

32. Schüle S, Friess W, Bechtold-Peters K, Garidel P. Conformational analysis of protein secondary structure during spray-drying of antibody/ mannitol formulations. Eur J Pharm Biopharm. 2007;65(1):1-9.

33. Maury M, Murphy K, Kumar S, Mauerer A, Lee G. Spray-drying of proteins: effects of sorbitol and trehalose on aggregation and FT-IR amide I spectrum of an immunoglobulin G. Eur J Pharm Biopharm. 2005;59(2):251-261.

34. Zhou S, Deng X, Li X. Investigation on a novel core-coated microspheres protein delivery system. J Control Release. 2001;75(1-2):27-36.

35. Chew NY, Chan HK. Use of solid corrugated particles to enhance powder aerosol performance. Pharm Res. 2001;18(11):1570-1577.
Drug Design, Development and Therapy

\section{Publish your work in this journal}

Drug Design, Development and Therapy is an international, peerreviewed open-access journal that spans the spectrum of drug design and development through to clinical applications. Clinical outcomes, patient safety, and programs for the development and effective, safe, and sustained use of medicines are a feature of the journal, which

\section{Dovepress}

has also been accepted for indexing on PubMed Central. The manuscript management system is completely online and includes a very quick and fair peer-review system, which is all easy to use. Visit http://www.dovepress.com/testimonials.php to read real quotes from published authors.

Submit your manuscript here: http://www.dovepress.com/drug-design-development-and-therapy-journal 